\title{
Stress perception, lifestyle behaviors, and emotional intelligence in undergraduate nursing students
}

\author{
Nagia Saleh Ali ${ }^{* 1}$, Omar Samir $\mathrm{Ali}^{2}$ \\ ${ }^{1}$ School of Nursing, Ball State University, Muncie, IN, United States \\ ${ }^{2}$ Center for Excellence in Nursing Education, Sigma Theta Tau International, Indianapolis, IN, United States
}

Received: December 21, 2015

DOI: $10.5430 /$ jnep.v6n10p16
Accepted: May 15, 2016

Online Published: May 25, 2016

URL: http://dx.doi.org/10.5430/jnep.v6n10p16

\begin{abstract}
Background: The ongoing curricular changes in nursing programs have resulted in a marked increase in the stress experience of nursing students. Lifestyle behaviors are recognized as essential components of stress reduction and wellbeing. These behaviors include consuming a healthy diet, engaging in exercise, and seeking social support. Emotional intelligence (EI) was also included because of its positive effects on subjective well-being and its mitigating effects on stress. The purpose of this study was to examine the link among stress perception, lifestyle behaviors, and EI.

Methods: Sixty-three undergraduate nursing students with a mean age of 22 years, electronically completed tools that addressed stress perception, diet, exercise, social support, EI, and demographic characteristics. Descriptive statistics, correlational analysis, and ANOVA were used to analyze data.

Results: Students reported a tendency toward perceiving a high level of stress, scored high on EI, sought social support, reported friends as the more frequent social support providers, tended to consume healthy diet, and were more likely to exercise. EI was correlated with the consumption of healthy diet, emotional and instrumental social support. Consumption of a healthy diet was also correlated with exercise participation. The social support constructs of emotional, instrumental, and venting of emotions were correlated with each other.

Conclusion: The study results indicate this sample of nursing students participated in a healthy lifestyle and reported high EI. Assessing stress perception needs to be focused on nursing-related stress.
\end{abstract}

Key Words: Nursing students, Stress, Lifestyle behaviors, Emotional intelligence

\section{INTRODUCTION}

Stress is experienced when an individual perceives their available resources are insufficient to adapt to a situation. Emotional distress among nursing students is a common phenomenon. ${ }^{[1]}$ Some common stressors include academic demands, unfamiliar clinical situations, and fear of academic and clinical failure. ${ }^{[1]}$ Effective stress management is essential for these students. Failure to effectively manage sustained stress may result in a decrease in the total wellbeing of the individual, insomnia, irritability, anxiety, and depression. ${ }^{[1]}$

Stress management begins with the individual. Stress reduction is one of the basic foundational strategies for maintaining one's health at any age. To be successful in the academic setting, nursing students must adopt successful stress reduction behaviors as part of a healthy lifestyle. These behaviors in-

\footnotetext{
*Correspondence: Nagia Saleh Ali; Email: nali@ bsu.edu; Address: School of Nursing, Ball State University, 2000 University Avenue, Muncie, IN 47306, United States.
} 
clude practicing good nutritional habits, engaging in regular exercise, and seeking social support. Healthy lifestyle behaviors may enable the individual to effectively deal with stress. Also, being an effective communicator is a healthy behavior that leads to stress reduction. An effective communicator is an emotionally intelligent (EI) person who is aware of one's and others' emotions. During emotionally-charged stressful situations, the individual is able to identify the stressor early, understand the trigger, and deal with it effectively. ${ }^{[2]}$ This awareness is essential for nursing students encountering new stressful situations. Emotional intelligence would act like an intervening factor between mental health and stress reduction. ${ }^{[2]}$ The EI skill can be taught and integrated into curriculum to provide nursing students with control over their emotions.

Stress severity, acute or chronic, alters food selection and healthy nutrition. ${ }^{[3]}$ Acute stress is associated with suppression of appetite due to the release of adrenaline and noradrenaline. Chronic stress is associated with elevated cortisol, the stress hormone, resulting in increased appetite, especially the consumption of sweet, fatty meals. ${ }^{[3]}$ A previous study in working adults found that participants ingested high caloric meals, high in sugar and fat, in stressful days and ate less on non-stressful days. ${ }^{[4]}$ Healthy nutrition as one component of health-promoting behaviors among nursing students was found to be inadequate. ${ }^{[5,6]}$ Nursing students who experienced stress reported inability to consume healthy meals, because of the effect of stress itself or their lack of awareness of the link between stress reduction and good nutrition. ${ }^{[7]} \mathrm{Al}-$ though emotional stress is associated with over eating of high carbohydrate and fatty meals, maintaining a well-balanced nutrition may decrease the craving for these kinds of foods during the stress reaction.

Similar to the link between stress and food intake, the relationship between stress and exercise has been examined. Exercise reduces stress perception through improving one's ability to cope with stress. ${ }^{[8]}$ Exercise in any form can increase the body's production of the brain's feel-good endorphins. One of those being serotonin which improves mood, energy level, sleep, and promotes self-confidence. ${ }^{[9]}$ Among college students, previous studies have shown that those who regularly exercise perceive less stress, have less deleterious effect of stress on the heart, exhibited enhanced cardiac recovery after stressful event, and prevented the occurrence of stress-induced immunosuppression. ${ }^{[10,11]}$ Previous studies also showed that although nursing students were aware that exercise is a health-promoting behavior, they were not regularly engaging in physical activities due to the stress of academic demands, and the practice of risky behaviors such as alcohol consumption. ${ }^{[7,12-14]}$ Government and

Published by Sciedu Press organizational guidelines for healthy exercise performance include at least 30 minutes of moderate-intensity physical activity five days/week or 20 minutes of vigorous activity three days/week. ${ }^{[15]}$

The effects of social support on stress reduction have been well documented in the literature. Cobb $^{[16]}$ proposed that social support, perceived or received, makes the receiver of support feel cared for, loved, valued, and esteemed. Emotional support buffers the stress reaction and lowers cortisol responses to stress while instrumental social support provides assistance to others such as information, finance, resources, or services. ${ }^{[17]}$ Two studies, one conducted in UK and the other in the US, found that social support was a beneficial factor in helping nursing students cope with stress. ${ }^{[18,19]} \mathrm{Sim}$ ilarly, in Turkey, a recent study found that nursing students who were seeking social support coped better with stress. ${ }^{[20]}$ Further, a study found that nursing students with high EI also reported a large social support network. ${ }^{[21]}$ Both high EI and a large social support network enabled nursing students to better deal with stress through the mediating influence of effective, multiple social interactions. ${ }^{[21]}$

Emotional self-awareness and recognition of emotions in others are contributing factors to effective communication and subsequent management of stress that may arise in social interactions. EI is the measure of one's ability to recognize, interpret and then act upon the emotions of self and others. ${ }^{[22,23]}$ Nursing students are often placed in unfamiliar emotionally charged social situations. EI can influence the nursing student's ability to critically think, learn effectively, make proper decision, and empathize with patients and family members. ${ }^{[2]}$ The relationship between stress management and EI has been investigated. Studies conducted among American and British nursing students found that participants with higher EI perceived less stress and coped better due to the mediating effect of effective social interaction. ${ }^{[21,25]}$ A 2010 Canadian study conducted among baccalaureate nursing students found that 4 th year students exhibited significantly $(p<.05)$ better stress management skills than 1st year students. ${ }^{[26]}$ Further, a more recent study found that progression in the nursing program was significantly $(p<.05)$ associated with high EI functioning and less stress. ${ }^{[27]}$

In summary, although there are research studies that addressed stress and EI among nursing students, there have been no studies that investigated how the lifestyle behaviors of nutrition, exercise, social support, and EI ability affect stress perception. The purpose of this study was to examine the link among stress perception, lifestyle behaviors, and EI. 


\section{Research questions}

(1) What is the relationship among stress perception lifestyle behaviors, and EI?

(2) What do students do to reduce the effect of stress on them?

\section{Methods}

The study used a cross sectional design. Data were electronically collected from recruited undergraduate nursing students in a Midwestern university. Recruitment for the study was made by face-to-face encounters of the principal investigator with on campus undergraduate nursing students. Approximately 250 students were present in the different classrooms during recruitment. However, the online access of the anonymous electronic survey was completed only by sixty-three students, with a $25 \%$ response rate. The institutional review board approved the study. Return of the questionnaires indicated agreement to participate.

The self-report questionnaires included 5 instruments and the demographic characteristics form. The demographic data requested were nursing level, gender, age, marital status, living arrangement, and ethnic background. Stress perception was assessed by a one ratio-level statement "On a scale of 1 to 10 , where 1 is little or no stress and 10 is extremely stressed, where are you now?" Participants selected a number.

Eating pattern was measured by the Nutrition subscale of the Health-Promoting Lifestyle Profile II (HPLP II). ${ }^{[28]}$ It has 9 items and is constructed as 4-point Likert scale, with "never" as 1 and "routinely" as 4 . Possible scores are 9 to 36 , with higher scores indicating a better eating pattern. Nutrition items addressed consumption of diet essential for vitality and its ability to reduce less craving to stress-inducing high carbohydrate and fatty meals. Validity and reliability of the nutrition subscale have been reported as part of the whole HPLP II and has been used extensively in research. Cronbach's alpha in this study was 0.795 .

Exercise participation was assessed by a measure developed by the authors. Participants were asked whether they were physically active for the purpose of exercise (yes/no). If they selected yes, they were asked to identify how many days per week they exercised and the duration of each exercise session. An exercise score was obtained by multiplying the number of days per week spent exercising by the number of minutes spent per session. This method yielded minutes of weekly exercise.

Seeking social support was measured by the 6 items social support subscale of the Carver Brief COPE tool. ${ }^{[29]}$ Participants responded on a four-point Likert scale, with 1 as "I haven't been doing this at all" and 4 as "I've been doing this a lot." Two items addressed seeking instrumental support, two items for emotional support, and two items for venting of emotions. Possible range of scores for the 6 item measure is 6 to 24, with higher scores indicating frequent seeking of social support. Validity of the Brief COPE was demonstrated using three studies. ${ }^{[29]}$ Brief COPE has been used frequently in studies examining stress and coping. Cronbach's alpha for the social support ranged from $0.75-0.85 .{ }^{[29]}$ Cronbach's alpha in this study for the 6 items was 0.854 . Also, participants were asked to identify their social support providers.

The EI measure was assessed by the Schutte Emotional Intelligence Scale (SEIS). ${ }^{[23]}$ Factor analysis of the original 62 item tool resulted in a one meaningful 33-item factor. Items addressed emotions appraisal/expression, emotions regulation, and emotion utilization to reduce stress, resolve an issue, or adapt in a specific situation. Participants responded on a 5-point Likert scale with 1 as strongly disagree and 5 as strongly agree. Cronbach's alpha was 0.90 for the 33-item scale. ${ }^{[23]}$ Possible range of scores is 33 to 165 . Higher score indicate higher EI ability. Cronbach's alpha of the EI tool in this study was 0.901 .

\section{Statistical analysis}

Continuous variables were expressed as means and standard deviation. Dichotomous variables were expressed as frequencies and percentages. Pearson's correlation analysis was used to examine the link among the continuous variables. Analysis of variance (ANOVA) was used to examine the three levels of stress groups by the continuous and the demographic variables. The SPSS version 23.0 for the Macintosh (SPSS Inc., IL) was used to analyze data.

\section{RESULTS}

Descriptive findings for the study participants appear in Table 1 . The majority of the sample was women, whites, single, 22 years old, living with other people, and senior nursing students. Participants reported high stress perception with a mean of almost 7 at a 1 to 10 scale with 1 being "little or no stress" and 10 being "extreme stress". Level 1 and 2 of the stress perception scale was not selected by any participant. Perception of stress was further divided into three groups; low (level 3, 4, 5), moderate (level 6, 7), and high (level 8, 9, 10) (see Table 1). It was clear that there was a similarity in the number and percentages of participants in the three stress perception groups. The respondents scored high on the EI measure, seeking social support, including emotional and instrumental support, venting of emotions, and consumption of a healthy diet. Further, more than half of the sample reported engaging in physical activities, with a minimum of one day 
per week and a maximum of 7 days. The average duration of exercise participation reported was more than 2 hours, with a minimum of 15 minutes and a maximum of 2 hours (see Table 1).

Table 1. Descriptive statistics of the study variables and characteristics of the sample

\begin{tabular}{|c|c|c|}
\hline Variable & n (\%) & Range of scores, $\mathrm{M}(S D)$ \\
\hline \multicolumn{3}{|l|}{ Nursing levels $(\mathrm{N}=59)$} \\
\hline First year (sophomore) & $23(39.0 \%)$ & \\
\hline Second year (junior) & $11(18.6 \%)$ & \\
\hline Third year (senior) & $25(42.4 \%)$ & \\
\hline Age $(\mathrm{N}=59)$ & & $\begin{array}{l}\text { Range of age: 18-49, } \\
22.08 \text { (5.51) }\end{array}$ \\
\hline \multicolumn{3}{|l|}{ Marital status (N=59) } \\
\hline Single & $53(89.9 \%)$ & \\
\hline Married & $6(10.2 \%)$ & \\
\hline \multicolumn{3}{|l|}{ Living arrangement $(\mathrm{N}=59)$} \\
\hline Live alone & $11(18.6 \%)$ & \\
\hline Live with my significant other & $7(11.9 \%)$ & \\
\hline Live with others & $41(69.5 \%)$ & \\
\hline \multicolumn{3}{|l|}{ Gender (N=59) } \\
\hline Female & 58 (98.3\%) & \\
\hline Male & $1(1.7 \%)$ & \\
\hline \multicolumn{3}{|l|}{ Ethnic background (N=59) } \\
\hline Whites & $53(89.8 \%)$ & \\
\hline Blacks & $3(5.1 \%)$ & \\
\hline Hispanics & $2(3.4 \%)$ & \\
\hline Mixed & $1(1.7 \%)$ & \\
\hline \multicolumn{3}{|l|}{ Stress perception $(\mathrm{N}=60)$} \\
\hline Low stress perception group & $19(32 \%)$ & Range of scores: 1-10, \\
\hline Moderate stress perception group & $18(30 \%)$ & $6.63(2.02)$ \\
\hline High stress perception group & $23(38 \%)$ & \\
\hline Emotional intelligence $(\mathrm{N}=63)$ & & $\begin{array}{l}\text { Range of scores: } \\
33-165,127.94(12.03)\end{array}$ \\
\hline \multicolumn{3}{|l|}{ Seeking social support $(\mathrm{N}=61)$} \\
\hline $\begin{array}{l}\text { Seeking emotional support } \\
\text { Venting of emotions }\end{array}$ & & $\begin{array}{l}\text { Range of scores: 6-24, } \\
16.20(4.02)\end{array}$ \\
\hline Instrumental social support & & Range of scores: 2-8, \\
\hline Social support providers & & $5.87(1.42)$ \\
\hline Friends & $91.5 \%$ & Range of score: $2-8$, \\
\hline Spouse/relatives & $83.1 \%$ & 4.99 (1.59) \\
\hline Classmates & $55.9 \%$ & Range of scores: 2-8, \\
\hline None & $3.4 \%$ & $5.34(1.78)$ \\
\hline Do not need one & $3.4 \%$ & \\
\hline Nutrition $(\mathrm{N}=61)$ & & $\begin{array}{l}\text { Range of scores: 9-36, } \\
24.68(5.04)\end{array}$ \\
\hline \multicolumn{3}{|l|}{ Exercise participation $(\mathrm{N}=60)$} \\
\hline Yes & 35 (58.3\%) & \\
\hline No & 25 (39.7\%) & \\
\hline Exercise minutes/week & & 131.167 (138.77) \\
\hline
\end{tabular}

${ }^{\#}$ More than one social support providers was chosen

Pearson's correlations among the continuous variables of the study appear in Table 2. EI was significantly correlated with nutrition, emotional and instrumental social support. Nutrition was correlated with exercise participation. Seeking emotional support was correlated with venting of emotions and with instrumental social support. Also, venting of emotions was correlated with instrumental social support. Stress perception was not correlated with any variable (see Table
2). The ANOVA test was used to examine the three groups of stress perception, low, moderate, high by all the lifestyle behaviors, EI, and demographics, but no significant findings were found.

Results of the qualitative findings about what participants did to reduce the effect of stress on them appear in Table 3. Qualitative comments expressed were related to stress in general and stress specific to nursing. Qualitative comments reveal several common stress-reducing behaviors used by nursing students such as listening to music, praying, eating a balanced diet, making priority of tasks, avoiding procrastination, taking frequent breaks, and talking with others.

\section{Discussion}

This study investigated the associations among stress perception, lifestyle behaviors, and EI. Although stress perception was expressed toward the high end of the stress scale, the low, moderate, and high stress groups were similar in their sizes. This similarity in the size of stress groups indicates lack of variability of the stress variable and this might have contributed to its lack of association with all other variables of the study. Additionally, the stress question used in this study was geared toward general assessment of stress rather than focusing on specific stressors of nursing education. Also, stress perception might be predicted by the nature of the stressor, its intensity, frequency, and past method used to alleviate similar ones. For example, stress perception resulting from fear of clinical failure is not similar to stress perception because of having unsatisfactory clinical day. Qualitative model approach can capture the lived experience of stress among nursing students.

Nurse educators need to incorporate self-care stress management skills for nursing students in curricula at all levels. Stress management strategies should be incorporated in the different nursing courses. ${ }^{[30]}$ Nurse educators also experience stress, similar to their students, and sharing their coping strategies will help students see the educator role modeling in balancing personal and professional lives. ${ }^{[30]}$ Availability of on-campus classes that teach breathing exercises and meditation may also help stressed nursing students. Reflection has also been advocated as a strategy that may help nursing students develop self-awareness, recognize stressful events, re-describe the socialization encounter, identify how the stressful event was handled, and self-evaluate behaviors undertaken to reduce stress. ${ }^{[31]}$ Other approaches used to decrease anxiety and reduce stress among nursing students included biofeedback and mindful meditation. ${ }^{[32]}$ Although strategies and intervention methods used to decrease stress are successful at the time of their implementation, they need to be repeated semester after semester since academic de- 
mands are continuing until nursing students graduate. ${ }^{[33]}$

Participants did well in the areas of lifestyle behaviors, including diet, exercise, seeking social support, and adopting an emotionally intelligent approach in stressful situation. Participants probably conceptualized that the practice of a healthy lifestyle is good for their total well-being and, therefore, exhibited good behaviors. Not only stress management strategies must emphasize the link between the detrimental effect of stress on physical and psychological health, but also promote regular practice of a healthy lifestyle as protective and enabling behaviors. The qualitative findings of what students do to reduce stress reveal their awareness of what temporarily relief their acute stress. Nurse educators need to emphasize to nursing students that stress reduction is a continuous process and the practice of healthy lifestyle behaviors puts the foundation to their empowerment to perceive less stress, even when an event is highly stressful.

EI was correlated with the consumption of healthy nutrition. The authors do not have clear reasons for that correlation. One possible explanation is that people who tend to consume healthy meals are consciously aware of their eating pattern. This conscious awareness of meal selection also might have been evident in other skills such as EI and engaging in exercise; both variables were supported in this study.

Table 2. Correlation matrix of all variables

\begin{tabular}{|c|c|c|c|c|c|c|c|}
\hline Variable & $\begin{array}{l}\text { Emotional } \\
\text { intelligence (EI) }\end{array}$ & Nutrition & Exercise & $\begin{array}{l}\text { Stress } \\
\text { perception }\end{array}$ & $\begin{array}{l}\text { Emotional social } \\
\text { support }\end{array}$ & $\begin{array}{l}\text { Venting of } \\
\text { emotions }\end{array}$ & $\begin{array}{l}\text { Instrumental } \\
\text { social support }\end{array}$ \\
\hline EI & & $.255^{*}$ & .046 & -.027 & $.357^{* *}$ & -.016 & $.259^{*}$ \\
\hline Nutrition & & & $.302^{*}$ & -.060 & .190 & -.122 & .224 \\
\hline Exercise & & & & .063 & .170 & -.056 & .106 \\
\hline $\begin{array}{l}\text { Stress } \\
\text { perception }\end{array}$ & & & & & .065 & .031 & .060 \\
\hline $\begin{array}{l}\text { Emotional } \\
\text { social support }\end{array}$ & & & & & & $.396^{* *}$ & $.705^{* *}$ \\
\hline $\begin{array}{l}\text { Venting of } \\
\text { emotions }\end{array}$ & & & & & & & $.542^{* *}$ \\
\hline
\end{tabular}

Table 3. Summary of qualitative participants' comments on how to reduce the effect of stress on them

- Gain perspective, whatever is happening is not the end of the world

- Listen to music, pray, sleep it off, watch Netflix movie, draw, color

- Run, weight lift, do yoga, meditate, dance and practice deep breathing

- Deal with the stressor itself

- Eat balanced diet and confide in my friends, play with cat

- Go out with my friends to get my mind off things

- Make priority, and stay organized and on the top of things

- Do a list of things to be done and cross them off when completed

- Get mad and grumpy with everyone

- Drink plenty of fluid like diet coke

- Think of things one day at a time

- Finish school work and avoid procrastination

- Take frequent breaks

- Talk with my clinical group and classmates

There were significant correlations between EI and emotional social support and EI with instrumental social support. This was not a surprising finding since EI and social support share common components such as interpersonal relationship, emotions, recognition of emotions, and appraisal of needs. Also, people who score high in EI might have the insight to seek social support when needed. Use of social support and EI skills by nursing students are in keeping with other study results. ${ }^{[18-21,25-27]}$ Also, in this study, participants reported multiple social support providers, although the size of their social support network was not determined. Lastly, the significant relationship among the three scales of social support: emotional, venting of emotions and instrumental is a selfexplanatory phenomenon and validate the measure used in this study. ${ }^{[29]}$

\subsection{Limitations}

One of the study limitations is the small sample size. The electronic data collection took place at the beginning of the fall semester of 2015 when students receive multiple e-mail messages from different sources. The message about the study might have been deleted accidentally, intentionally, or lost as junk mail. Also, participants were not offered any incentive to participate such as extra points or a monetary reward. It is recommended that other methods of recruitments of nursing students be used in future studies. Further, the study was conducted in one school of nursing at a Midwestern university. Limitations deter the generalization of the study findings to nursing students at other universities. Future studies need to include large sample size, who are from different locations.

\subsection{Conclusion}

Results of the study indicate participants exhibited EI ability and reported the practice of healthy lifestyle behaviors. In- 
terventions undertaken to manage stress need to incorporate strategies targeting stress reduction, promotion of a healthy lifestyle, and developing emotional competence in nursing students. Measurement of stress perception needs to be specific to nursing stressors. Also, a qualitative approach such as the lived experience of the phenomenon of stress among nurs- ing students is recommended. This study can be replicated to compare the investigated variables among undergraduate and graduate students.

\section{CONFlicts of InTEREST Disclosure}

The authors declare that there is no conflict of interest.

\section{REFERENCES}

[1] Chernomas WM, Shapiro C. Stress, depression, and anxiety among undergraduate nursing students. International Journal of Nursing Education Scholarship. 2013; 10: 255-266.

[2] Kadda O. Emotional intelligence on nursing as an anxiety management tool. Health Science Journal. 2014; 8(2): 152-153.

[3] Takeda E, Terao J, Yutoka N, et al. Stress and human nutrition. The Journal of Medical Investigation. 2004; 51: 139-145. PMid:15460899. http://dx.doi.org/10.2152/jmi.51.139

[4] Ng DM, Jeffery RW. Relationship between perceived stress and health behaviors in a sample of working adults. Health Psychology. 2003; 22: 638-642. PMid:14640862. http://dx.doi .org/10.10 $37 / 0278-6133.22 .6 .638$

[5] Bryer J, Cherkis F, Raman J. Health-promotion behaviors of undergraduate nursing students: a survey analysis. Nursing Education Perspectives. 2013; 34(6): 410-415. http://dx. doi.org/10.54 80/11-614

[6] Al-Kandari F, Vidal VL. Correlation of the health-promoting lifestyle, enrollment level, and academic performance of college of nursing students in Kuwait. Nursing and Health Sciences. 2007; 9: 112-119. PMid:17470185. http://dx.doi.org/10.1111/j.1442-2018. 2007.00311.x

[7] Pawloski LR, Davidson MR. Physical activity and body composition analysis of female baccalaureate nursing students. Nurse Education in Practice. 2003; 3: 155-162. http://dx.doi.org/10.1016/S 1471-5953(02) 00109-9

[8] Stults-Kolehmainen MA, Sinha R. The effect of stress on physical activity and exercise. Sports Medicine. 2014; 44(1): 81121. PMid:24030837. http://dx.doi.org/10.1007/s40279-0 13-0090-5

[9] Greenwood BN, Fleshner M. Exercise, stress resistance, and central serotonergic systems. Exercise and Sport Sciences Reviews. 2011; 39(3): 140-149. PMid:21508844. http://dx.doi.org/10.1097 /JES.0b013e31821f7e45

[10] Skirka N. The relationship of hardiness, sense of coherence, sport participation, and gender to perceived stress and psychological symptoms among college students. Journal of Sport Medicine and Physical Fitness. 2000; 40: 63-70. PMid:10822911.

[11] Nyuyen-Michel ST, Unger JB, Hamilton J, et al. Associations between physical activity and perceived stress/hassles in college students. Stress and Health. 2006; 22(3): 179-188. http://dx. doi.o $\mathrm{rg} / 10.1002 / \mathrm{smi} .1094$

[12] Clement M, Jankowski L, Bouchard L, et al. Health behavior of nursing students: a longitudinal study. Journal of Nursing Education. 2002; 41(6): 257-265. PMid:12096774.

[13] Shriver CB, Scott-Stiles A. Health habits of nursing versus nonnursing students: a longitudinal study. Journal of Nursing Education. 2000; 39(7): 308-314. PMid:11052653.

[14] FitzGerald LZ. Categorization and determinants of physical activity among nursing students. Journal of Nursing Education and Practice. 2015; 5(5): $10-20$

Published by Sciedu Press
[15] USDHHS, Healthy People 2020. 2014

[16] Cobb S. Social support as a moderator of life stress. Psychosomatic Medicine. 1976; 98: 300-314. http://dx.doi.org/10.1097/0 0006842-197609000-00003

[17] Bolger N, Amarel D. Effects of social support visibility on adjustment to stress: Experimental evidence. Journal of Personality and Social Psychology. 2007; 92: 458-475. PMid:17352603. http://dx.doi.org/10.1037/0022-3514.92.3.458

[18] Gibbons C, Dempster M, Moutray M. Stress, coping and satisfaction in nursing students. Journal of Advanced Nursing. 2010; 67(3): 621632. PMid:21077931. http://dx.doi.org/10.1111/j.1365-2 648.2010.05495.x

[19] Wolf L, Studham AW, Ross R. Predictors of stress and coping strategies of US accelerated vs. generic baccalaureate nursing students: An embedded mixed methods study. Nursing Education Today. 2015; 35: 201-205. PMid:25127928. http://dx.doi.org/10.1016/j .nedt. 2014.07.005

[20] Yesil P, Ozyunc G. Personal charcteristics and styles of coping with stress of nursing students of a university in Turkey. Journal of Nursing Education and Practice. 2015; 5(5): 73-81. PMid:26504502.

[21] Montes-Berges B, Augusto JM. Exploring the relationship between perceived emotional intelligence, coping, social support and mental health in nursing students. Journal of Psychiatry and Mental Health Nursing. 2007; 14: 163-171. PMid:17352779. http://dx.doi.o $\mathrm{rg} / 10.1111 / \mathrm{j} .1365-2850.2007 .01059 \cdot \mathrm{x}$

[22] Salovey P, Mayer JD. Emotional intelligence. Imagination, Cognition and Personality. 1990; 9(3): 185-211.

[23] Schutte NS, Malouff JM, Hall LE, et al. Development and validation of a measure of emotional intelligence. Personality and Individual Difference. 1998; 25(2): 167-177. http://dx. doi.org/10.1016 /S0191-8869(98)00001-4

[24] Smith KB, Profetta-McGrath J, Cummings GG. Emotional intelligence and nursing: an integrative literature review. International Journal of Nursing Studies. 2009; 46: 1624-1636. PMid:19596323. http://dx.doi.org/10.1016/j.ijnurstu.2009.05.024

[25] Por J, Barriball L, Fitzpatrick J, et al. Emotional intelligence: Its relationship to stress, coping, well-being and professional performance in nursing students. Nurse Education Today. 2011; 31: 855-860. PMid:21292360. http://dx.doi.org/10.1016/j.ned t. 2010.12 .023

[26] Benson G, Ploeg J, Brown B. A cross-sectional study of emotional intelligence in baccalaureate nursing students. Nursing Education Today. 2010; 30: 49-53. PMid:19586691. http://dx.doi.org/1 $0.1016 / j$.nedt. 2009.06.006

[27] Collins S. Emotional intelligence as a noncognitive factor in student registered nurse anesthetists. American Association of Nurse Anesthetists Journal. 2013; 81(6): 465-472.

[28] Walker S, Sechrist K, Pender N. The health promoting lifestyle profile: Development and psychometric characteristics. Nursing Research. 1987; 36: 76-81. PMid:3644262. 
[29] Carver CS. You want to measure coping but your protocol's too long: Consider the Brief COPE. International Journal of Behavioral Medicine. 1997; 4(1): 92-100. PMid:16250744. http://dx.doi.o $\mathrm{rg} / 10.1207 / \mathrm{s} 15327558$ ijbm0401_6

[30] Clark CS, Pelicci G. An integral nursing education: a stress management and life balance course. International Journal of Human Caring. 2011; 15(1): 13-22.

[31] Horton-Deutsch S, Sherwood G. Reflection: an educational strategy to develop emotionally-competent nurse leaders. Journal of Nursing Management. 2008; 16: 946-954. PMid:19094107. http: //dx.doi.org/10.1111/j.1365-2834.2008.00957.x

[32] Ratanasiripong P, Park JF, Ratanasiripong N, et al. Stress and anxiety management in nursing students: biofeedback and mindfulness meditation. Journal of Nursing Education. 2015; 54(9): 520-524 PMid:26334339. http://dx.doi.org/10.3928/01484834-201 50814-07

[33] Galbraith ND, Brown KE. Assessing intervention effectiveness for reducing stress in student nurses: quantitative systematic review. Journal of Advanced Nursing. 2011; 67(4): 709-721. PMid:21214619. http://dx.doi.org/10.1111/j.1365-2648.2010.05549.x 